\title{
Investment Scenarios for Low Carbon Electricity in Europe
}

\author{
B. Shoai Tehrani ${ }^{1}$ and P. da Costa ${ }^{2}$ \\ ${ }^{1}$ Institut de Technico-Economie des Systèmes Energétiques, CEA Saclay, DEN/ DANS/I-tésé \\ 91191 Gif-sur-Yvette Cedex France - Phone +33 169086 523, Fax +33 169083 566, e-mail bianka.shoai-tehrani@cea.fr \\ and Laboratoire de Génie Industriel / épocc, Ecole Centrale Paris \\ ${ }^{2}$ Laboratoire de Génie Industriel / épocc, Ecole Centrale Paris \\ Grande Voie des Vignes 92295 Châtenay-Malabry Cedex France - e-mail pascal.da-costa@ecp.fr
}

\begin{abstract}
In a context of carbon emissions reduction, this article aims at widening the scope of the OECD - Nuclear Energy Agency (NEA) report entitled "The interaction of Nuclear Energy and Renewable: System Effects in Low Carbon Electricity System » (2012) to the European electric supply by studying the conditions of industrial investments in low carbon technologies over the next 30 years.

These conditions can be either favorable or not to, on the one hand, the renewable energies and, on the other hand, the nuclear technologies, according to 3 main dynamically quantified drivers:

1. "Technical change", i.e. relative evolutions of efficiency and costs of available technologies (gas, coal, wind...);

2. "Policy", i.e. incentive framework given by European energy policies (nuclear, climate...);

3. "Economic", i.e. structure of electricity markets (level of centralization...).

A total of 24 scenarios are developed using an imaginative approach, i.e. assuming different possibilities for the future change in 3 main drivers. Finally we have found:

- 2 scenarios of them prove to be the most favorable to renewable energies;

- 2 scenarios favorable to both renewable and nuclear, for the interaction of nuclear and renewable in the electricity system is not necessarily favorable to nuclear investment.

These scenarios are then discussed in view of the quantitative drivers mentioned above.
\end{abstract}

\section{Key words}

Low Carbon Economics, Electricity Investments, Renewable and Nuclear Energies.

\section{Introduction}

In a context of climate protection and carbon emission reduction in Europe, as in the European Climate Action and Renewable Energy Package (see [1]), this article addresses the issue of investment in low carbon technologies. Regarding the joint development of renewable and nuclear energies, the NEA [2] identifies the economic consequences on the whole electricity system of power generation based massively on these two kinds of technologies. Upstream from this nuclear and renewable based system, our article aims at understanding how these technologies could actually become major ones on the market, for more than $50 \%$ of power generation still comes from fossil fuel in Europe [3]. The evolution of the generation mix towards low carbon electricity depends of course on many factors such as climate and energy policies, but in the end is determined by the actual decisions of power generation companies, who will invest in new capacities in order to replace their ageing capacities and satisfy a growing demand. This is why we have chosen to focus on investors, i.e. power generation companies, and analyze their behavior regarding investments in generation capacities.

There are thus two research questions we seek to answer in this article: What are the drivers for investors' decisions on the European electricity market, regarding investments in power generation capacities? How do they affect the evolution of the European generation mix, and the development of low carbon technologies in the mix?

We focus on France, Germany, United Kingdom, Spain and Italy, for they represent $65 \%$ of EU27 power generation. The time horizon is fixed to roughly 2040, for most reference scenarios' time limit are situated between 2030 and 2050 ([1], [4]).

To identify the drivers to investors' decisions, we proceed by analyzing:

Historical aspects of the European generation mix constitution and of the European market liberalization;

- Investors' profiles through a few key characteristics such as the shareholding structure, market capitalization, annual revenue, generation mix;

- Technologies investments conditions such as costs and incentives.

In the end, 3 key drivers are identified, each driver being described by several variables. Scenarios for future generation mix are built upon a couple of low/high hypothesis for each driver. Structural analysis of the set of variables is conducted with tool MICMAC [5]\& [6] in order to assess the relative importance of the different variables and rank the scenarios.

\section{Generation Mix Constitution and Market Liberalization in Europe}

It is necessary as a first step of our analysis to look back on historical aspects, and mainly two of them: the constitution of the European generation mix from the fifties to now, in order to understand past investment choices, and the European market liberalization that 
started in the nineties, in order to understand which kind of context today's investors are confronted to.

This historical analysis shows that European countries have massively privileged local resources (such as coal in Germany) or the development of a locally well-mastered technology when local resources were poor (such as nuclear in France). This tendency was reinforced after the two oil shocks in the seventies, leading European power companies to insure security of supply at high costs. The driver to these decisions was the state policy, whose purpose was to ensure energy independency.

After the counter shocks of the eighties, a market reform occurred in Europe in the nineties, in order to create a unique European competitive market from all the national markets in place, often integrated monopolistic markets. The reform was unequally applied in the different countries (very much in the UK, which was a pioneer of liberalization and very little in France, where the the natural monopoly model was considered a success within the rule of the Ramsey-Boiteux pricing [7]), leading to various market structures and concentrations that will constitute very different environments for investors. The unification of the European market remains unachieved, mostly because of a lack of interconnections between countries [3]. Market structure is thus another driver for investors' decisions.

\section{Investors' Profiles}

The second step of our analysis consists in defining who the investors are and how their characteristics will influence their own investment decisions.

Investors' profiles can be analyzed through a few key characteristics that are:

- The shareholding structure, which will give an indication on the investment strategy of the company (private shareholders : institutional, public float, or state shareholders : state, ministry, local collectivity, and weight of the different types of shareholders);

- The market capitalization and annual revenue, that indicate the size of the company from a financial point of view and the size of the investments the company can support,

- The total annual production, that indicate the size of the company from an industrial point of view;

- The generation mix, that shows the expertise fields of the company;

- The market shares on the markets where the company is active, which show the international scope of the company.

As a result from this analysis, most of the power generation companies today are former historical operators who used to be in a dominant market position [3]. Their shareholders are state actors such as the government, a ministry, or local communities, institutional investors such as banks and insurance companies, and private shareholders (public float), the weight of each type of shareholders depending on the national position towards market reform and the particular history of the company. Their annual revenue and market capitalization represent several dozen billion $€$ and annual production around a hundred TWh. Their dominant technologies are mostly coal and gas, (and nuclear for EDF). Most of them have crossed the border of their initial market and started being active on neighboring markets: for instance EDF is present in UK and Italy, EOn in UK, Italy and Spain. We can also observe concentrating movements between these companies: as a few examples among many others, Italian operator ENEL owns Spanish one Endesa, French operator EDF owns British Energy, and Spanish operator Iberdrola owns Scottish Power.

Yet another type of profile seems to be emerging with the market reform, the one of small power companies. Such companies are generally young, dating from the nineties or years 2000 such as wind operator Theolia. Their shareholding structure have no state actors component; their revenue is around a few million $€$ and annual production less than $1 \mathrm{TWh}$. They mostly specialize in one technology since their size does not allow them to diversify, mostly recent technologies such as renewable or CCGT, and can be local or international operators, representing minor market shares in any case.

As we said above, national positions regarding the market reform differ from one country to another, which affects power generation companies' evolution. France, Germany and Spain tend to protect their historical operators on their inside markets and promote their international development thanks to the reform, as though UK and Italy are really promoting competition on their own market, with Italy limiting market shares for the different actors on the Italian market for instance. The evolution of investors' profiles towards multinational concentrated companies or towards small power operators will depend on global market structure evolution, in link with the market reform policies lead in EU countries.

\section{Investment Conditions in Electricity Generation Technologies}

After analyzing the history of the market and the investors themselves, the third step will look into the technologies and the investment conditions for each technology. All major power generation technologies are considered: coal, gas, nuclear, hydro, wind, solar. For each technology, investment conditions are examined: building and generation costs, and load factors, that will directly impact the expected profits, but also all the parameters that will make the technology more or less easy to acquire for the investor, which are building period, average size of the plant for this technology, technology complexity, variety of financing methods, positive and negative incentives coming from policies (such as carbon costs, subsidies for renewable, insurances from the government, or radical decisions such as nuclear phase-out decisions in Germany and Italy).

The review of these investment conditions shows strong differences from a technology to another; it is thus difficult to identify global trends in investment conditions for low carbon technologies as well as for fossil fuels based technologies [4].

In order to understand investment choices, it is relevant to confront investors' profiles and technologies' investment conditions: for instance, capitalistic investments such as coal or nuclear plants are a priori achievable only for companies with sufficient revenue and capitalization to support the building costs, and low capital cost technologies such as small renewable facilities are at all investors' reach. But the thorough investigation of 
investment conditions show that original financing methods such as conjoint investment from a power generation companies consortium or financing from longterm electricity purchasers can broaden the scope of companies able to make capitalistic investments.

The evolution of these investment conditions depend on both policies and technical progress, policies impacting investments through incentives, and technical progress being the key to cost reduction. However, among the technologies being studied, coal, gas, hydro and nuclear are considered to be time-tested and expect less progress than wind and solar ${ }^{1}$.

\section{Building of Scenarios}

\section{A. Assumptions}

The analysis has thus allowed us to identify three drivers for investors' decisions:

- Policy, i.e. incentive framework given by European energy policies;

- Economic driver, i.e. structure of electricity markets, with level of centralization, concentration and competition...

- Technical change, i.e. relative evolutions of efficiency and costs of available technologies for gas, coal, nuclear, hydro, solar, wind.

In order to build investments scenarios based on these drivers, it is necessary to define more precisely the key aspects of these drivers we have chosen to focus on and to extract from our previous analysis assumptions regarding their evolution in the time horizon of our study.

The policy driver actually contains four dimensions:

- Climate policy, which is divided into two aspects : carbon policy and renewable policy;

- Carbon policy, which will determine the incentives regarding carbon emissions, and promote low carbon energies, which are at the heart of our study. To describe climate policy we consider two relevant tools: carbon emission quotas that are currently used in Europe through the EU Emission Trading System, and carbon tax, as it being launched in the U.K. [9]. For our scenarios, we identify a strong climate policy scenario and a moderate climate policy scenario that can be quantified by their carbon price ranges, carbon pricing being the key tool of climate policy. Moderate climate policy would consist in carbon pricing increasing from a dozen \$/ton (today's price) to $\$ 45 / \mathrm{tCO}_{2}$ in 2040. Strong climate policy would increase carbon price up to $120 \$ / \mathrm{t} \mathrm{CO}_{2}$ in 2040 [4];

- Renewable policy, which is closely related to carbon policy, can be described

\footnotetext{
${ }^{1}$ It is true though that nuclear technology still experiences innovation, but even new generations of nuclear reactors (Generation III, Generation IV) are based on experienced concepts : Pressurized Water Reactors for Generation III, which is one of the most current concepts in operation today, and Sodium-Cooled Fast Reactors for Generation IV, the technology of which was experienced in France in the eighties with demonstrators Phenix and Superphenix, and is today in operation in Russia on a few reactors (BN-600, BN-800).
}

in Europe by 4 kinds of tools: feed-in tariffs, green certificates, tenders and fiscal incentives [9].

- Nuclear policy, for the use of this energy can be controversial according to the national context, the positions in the 5 studied countries being very different. For our scenarios, we identify the three positions currently observable and assume that they do not change within the considered period ${ }^{2}$ : France has adopted a strongly pro-nuclear position, UK a moderate pro-nuclear position, Germany, Italy and Spain an anti-nuclear position; for pro-nuclear countries, we add the "strike price" variable to describe the nuclear policy more accurately;

- Electricity market reform policy, which will have a direct influence on investors' environment and investors' profiles themselves. For our scenario elaboration, this driver is included in the second one: "economic driver".

The economic driver contains several aspects:

- The level of concentration and competition of the market that can be characterized by the number of actors present on the market and the HerfindahlHirschman Index $\left(\mathrm{HHI}^{3}\right)$;

- And related to that, the market policy lead by the country, which will have an influence on both the market structure through market reform policy and market coordination, which is essential to investors' decision.

As a first approach, we will consider that market reform policy is described by the choice to develop or not interconnections, and more generally, the electricity grid. The "market structure" driver will thus be considered under both angles of concentration and interconnections. We will have a high concentration and low concentration market assumptions using the HHI: as in the European Commission Guidelines about competition, we consider a market in which HHI is lower than 1000 as competitive and low concentrated whereas a market in which HHI is in excess of 2000 is highly concentrated. A high concentration hypothesis goes along with a low development of interconnections; a low concentration market with a strong development of interconnections. As for the market coordination aspect, coordination regarding investments, it is described by the different financing methods: corporate financing, project financing, hybrid method mixing the two latter or other original financing methods (for instance, financing coming from the future customers) [10] \& [11]. We consider the flexibility of choices in financing as a static decision variable and thus make no assumption regarding their potential evolution.

\footnotetext{
${ }^{2}$ This assumption may be considered a limit of the scenarios elaboration; nevertheless, such political positions commit long term industrial behaviors and for this reason assuming certain inertia of the pro or antinuclear position is relevant.

${ }^{3} \mathrm{HHI}$ definition, with $\mathrm{s}_{\mathrm{i}}$ the market share of firm $\mathrm{i}$ in the market, and $\mathrm{N}$ the number of firms:$$
H=\sum_{i=1}^{N} s_{i}^{2}
$$

The more HHI is low, the more the market is competitive, and the more $\mathrm{HHI}$ is high, the more the market is concentrated.
} 
The technical change driver corresponds mostly, as we said earlier, to the expected technical change for recent renewable technologies, i.e. wind and solar. For this driver, we make a high technical change assumption and a low technical change assumption. The technical change would impact construction costs, generation costs, and technical constraints of each technology: load factor, average size of plants, building period; WEO 2011 scenarios allow us to make estimates about expected cost reduction [4]. Since the impact on these different costs is quite homogenous according to the expected progress for one technology, overnight investment cost reduction is a relevant indicator: Table I gives orders of magnitude of investment cost reduction for the two assumptions, which shows that progress is mostly expected for solar technologies (PV and CSP).

Table I. Investment cost reduction between 2010 and 2040

\begin{tabular}{|l|c|c|}
\hline Technology & Low technical change & High technical change \\
\hline Onshore wind & $10 \%$ & $20 \%$ \\
\hline Offshore wind & $25 \%$ & $50 \%$ \\
\hline Solar PV (utility and rooftop) & $50 \%$ & $75 \%$ \\
\hline Concentrated solar power & $40 \%$ & $90 \%$ \\
\hline
\end{tabular}

As a result of the number of hypothesis:

- high and low assumptions for climate policy driver, economic driver, and technical change driver,

- $\quad$ and high, low and medium assumptions for nuclear policy

a total of 24 different scenarios are possible. Since we assume that nuclear policy is given data and remains unchanged, we have for each country 8 possible scenarios presented in next Table:

Table II. Scenarios and corresponding assumptions

\begin{tabular}{|l|l|l|l|}
\hline Scenario 1 & strong climate policy & high technical change & not concentrated \\
\hline Scenario 2 & strong climate policy & high technical change & concentrated \\
\hline Scenario 3 & strong climate policy & low technical change & not concentrated \\
\hline Scenario 4 & strong climate policy & low technical change & concentrated \\
\hline Scenario 5 & low climate policy & high technical change & not concentrated \\
\hline Scenario 6 & low climate policy & high technical change & concentrated \\
\hline Scenario 7 & low climate policy & low technical change & not concentrated \\
\hline Scenario 8 & low climate policy & low technical change & concentrated \\
\hline
\end{tabular}

Scenarios are classified from the most favorable to renewable investment to the least favorable, as we will explain in detail in section $B$.

\section{B. Structural analysis with MICMAC tool and Scenarios Description}

The different decision variables corresponding to the three main drivers are listed in Table III. The MICMAC method consists in assessing the relative influence of all variables upon another. For each variable, its influence on every other variable is quantified from 0 to 3 , the value 0 corresponding to no influence at all, and 3 to a strong influence. The letter $\mathrm{P}$ is used when a potential influence is sensed, but not clearly indentified. The values are used to fill a matrix called the Matrix of Direct Influences, each line containing the values attributed to the variable's influence on every variable in column. Therefore the lines show how much influence the variables have on the other ones and the columns show how much the variables depend on the other ones. Table IV shows the Matrix of Direct Influences in our case study.

Table III. Decision Variables for each Driver

\begin{tabular}{|l|l|}
\hline Carbon tax $\left(€ / \mathrm{tCO}_{2}\right)$ & Policy Driver \\
\hline $\mathrm{CO}_{2}$ quota & Policy Driver \\
\hline Feed-in tariffs for renewables $(€ / \mathrm{MWh})$ & Policy Driver \\
\hline Green certificates for renewables & Policy Driver \\
\hline Tenders for renewables & Policy Driver \\
\hline Fiscal incentive for renewables & Policy Driver \\
\hline Nuclear position & Policy Driver \\
\hline Nuclear strike price (€/MWh) & Policy Driver \\
\hline Stability of policy & Policy Driver \\
\hline HHI concentration index & Economic Driver \\
\hline Development of grid and interconnections & Economic Driver \\
\hline Corporate financing & Economic Driver \\
\hline Project financing & Economic Driver \\
\hline $\begin{array}{l}\text { Hybdrid financing method (corporate and } \\
\text { project financing) }\end{array}$ & Economic Driver \\
\hline Other original financing method & Economic Driver \\
\hline Construction costs (€/MW) & Technical Change Driver \\
\hline Generation costs (€/MWh) & Technical Change Driver \\
\hline Building period (year) & Technical Change Driver \\
\hline Size of plant (MW) & Technical Change Driver \\
\hline Load factor $(\%)$ & Technical Change Driver \\
\hline
\end{tabular}

Table IV. Matrix of Direct Influences

Using the Matrix of Direct Influences, the MICMAC tool

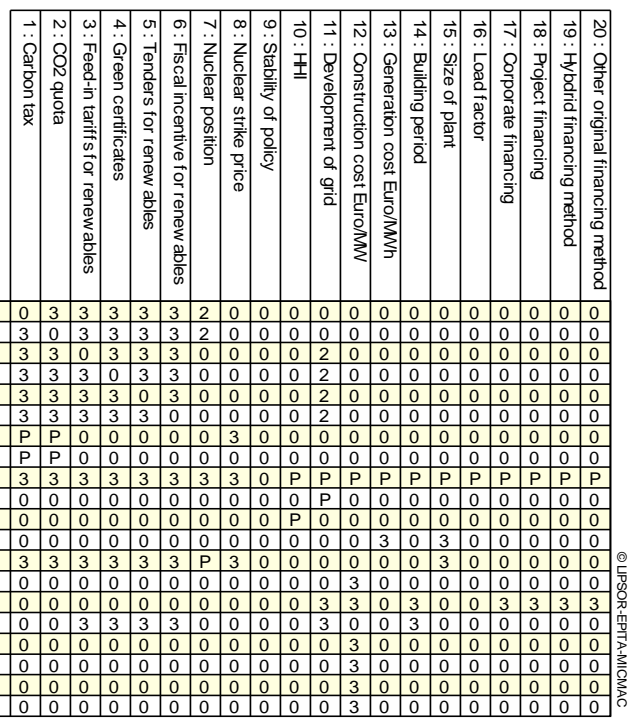

generates the Graph of Influences and Dependences. On this chart, the more a variable is far on the $\mathrm{x}$-axis, the more it is dependent on other variables; the more a variable is far up the y-axis, the more it has influence on other variables. Therefore the variables contained in the upper right corner of the chart, which have influence and depend on other variables, are called "critical variables" and are the most important variables of the set. The ones in the upper left corner of the chart have influence on other ones but do not depend on them and are thus exogenous: they are called "active variables". The ones in the bottom right corner depend on other variables but have no influence on them: they are called: "passive variables". Lastly, the ones in the bottom left corner of the chart have no influence on other variables and do not depend on them (exogenous): they are called:"inactive variables" and are the less important ones. 
Figure 1. Chart of direct influences and dependences

Figure 1 shows that the critical variables are all the Climate Policy variables. Active variables are: the

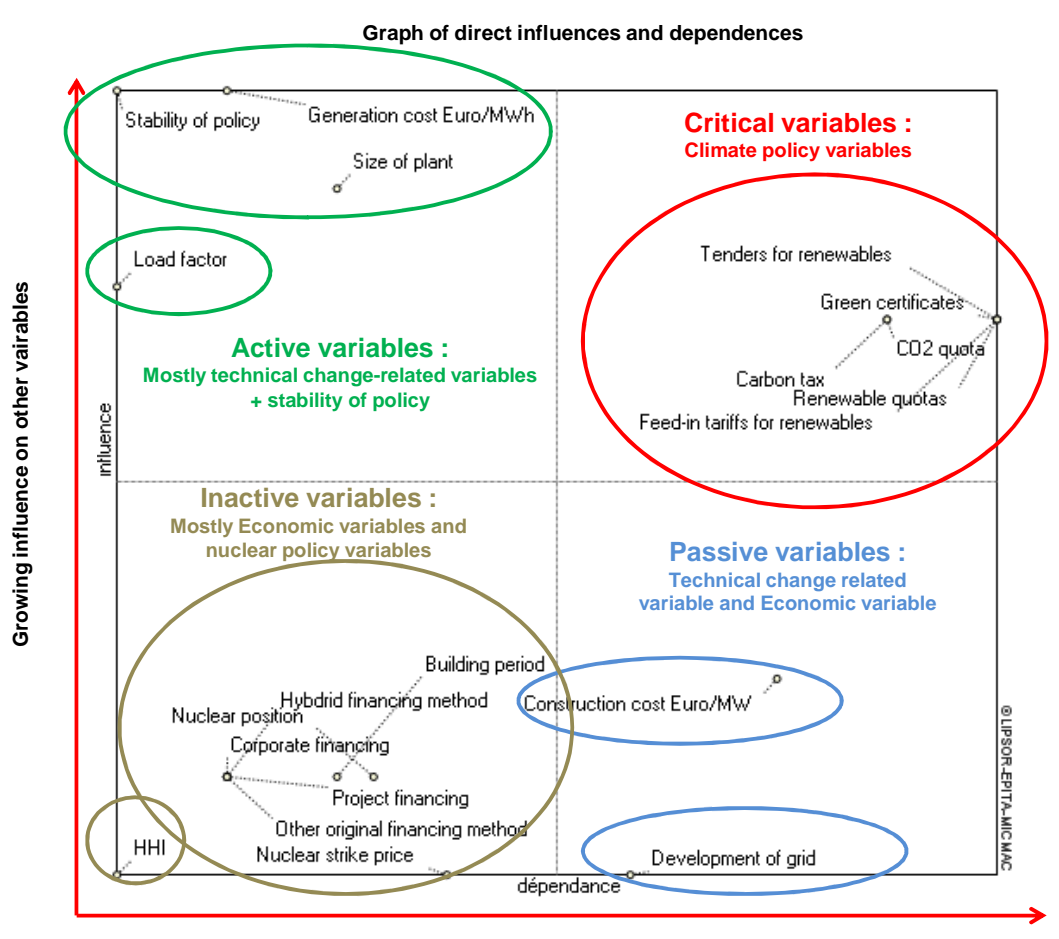

Growing dependence on other variables

stability of policy, and technical variables (generation costs, size of plant, load factor). Passive variables are technical change related: construction costs, and economic: development of grid. Inactive variables are most of the economic driver-related variables: financing methods and HHI, but also nuclear policy-related variables and the "building period" technical variable.

Since climate policy variable are the critical ones, scenarios ranked as favorable to low carbon policy are the ones with strong climate policy hypothesis i.e. scenarios 1 to 4 .

As our technical change hypothesis mostly corresponds to active variable, the ones most favorable to renewable are the ones that combine strong climate policy and high technical change, i.e. scenarios 1 and 2 . Since the hypothesis of a non-concentrated market implies multiple actors with small market shares, we could think that scenario 1 should be the most favorable ones to small investments like small renewable capacities. However, this assumption has limits, for scenario 1 does not exclude the possibility for capitalistic investments. The presence of multiple actors with small shares on a market does not necessarily mean they have little investments capacity: given the multinational profile of some investors, they may have important investment capacities despite their low market share. Moreover, market coordination and conjoint investments could also make capitalistic investments possible on a non-concentrated market. We thus consider scenarios 1 and 2 as both favorable to renewable.

Scenarios 3 and 4 would then be the ones favorable to low carbon time-tested technologies like nuclear and hydropower. However in the five countries studied here, hydraulic capacities are already well developed and submitted to strong environmental constraints and local opposition, which limits considerably investments new builds. Considering the nuclear policies in the different countries we focus on, scenarios 3 and 4 are favorable to nuclear in France and UK. In Germany, Italy, and Spain, they tend to be favorable to renewable again, though less than scenarios 1 and 2 and scenario 3 being slightly better than scenario 4 because of the market concentration factor.

Scenarios 1 to 4 are thus favorable to investment in both renewable and nuclear in France and UK, scenarios 1 and 2 tending to have more renewable investment and scenario 3 and 4 more nuclear investment. They are favorable to investment in renewable in Germany, Spain and Italy that are antinuclear countries. In all countries, fossil fuel based technology will lose market shares according to these scenarios. This means, especially for scenario 1, that back-up generation due to renewable intermittency will be ensured by non-intermittent hydraulic power and by nuclear power. It is necessary to point out that such a situation means a lower load factor for nuclear power and thus an important loss of competitiveness on generation costs [2]. As a consequence such massive low carbon investments situations would possible only if climate policies were strong enough to maintain nuclear investment attractive compared to fossil fuels and especially gas, or if technical change could bring solutions to intermittency such as mastering long term storage or interconnection between numerous sources. For investment in both nuclear and renewable, scenarios 3 and 4 are thus more favorable.

Scenarios 5 to 8 are the ones with low climate policy and are thus more favorable to coal and gas investments than the previous ones. Scenarios 5 and 6 are still favorable to renewable due to the technical change factor, scenario 5 being slightly more favorable due to market concentration factor. In these two scenarios and especially in scenario 5, gas investment will be promoted, for it is a low-capital, flexible technology technically suited to be a back-up capacity to renewable and economically suited to low load factors. Scenarios 7 and 8 are the least favorable ones to low carbon technologies, 7 being more favorable to gas than coal due to market concentration factor and 8 to both gas and coal.

More generally, among low carbon technologies, these scenarios tend to reduce nuclear investment in favor of gas and coal.

\section{Conclusion}

This study identifies the key drivers of investors' choices and builds scenarios of European generation mix evolution based on these drivers' evolution in the future. The structural analysis lead with the MICMAC tool shows that the economic driver is negligible compared to the two others. On a total of 24 scenarios, the favorable ones to renewable energies are the ones with strong climate policy. Nevertheless, the scenarios combining a strong climate policy with low technical change on our time horizon would represent a situation where renewable 
technologies have not achieved competitiveness in spite of prolonged effort. In the end only 2 have proved favorable to renewable energies: the scenarios combining strong climate policy and high technical change, regardless of the economic driver.

On a broader scale, the climate policy of Europe is determining for the whole international climate policy: the achievement of its objectives ( 3 x 20) would be a catalyst for an international climate policy, whereas its failure would discourage further attempts to build an international climate policy.

There are though a few limits to be mentioned: an indirect driver "public acceptance of the technology" exists and is for now included in the nuclear policy driver. However, public rejection could appear for renewable as well because of land use and landscape transformation.

Moreover the panel of technologies considers the technologies most commonly used at industrial scales and omits technologies that are not yet quite developed such as biomass, geothermal energy and carbon capture and storage.

\section{Acknowledgement}

We would like to thank Romain Farel (Laboratoire de Génie, Ecole Centrale Paris) for his help on using the MICMAC tool.

\section{References}

[1] P. Da Costa, P. Zagamé, P. Le Mouel, O. Gharbi and F. Pratlong, "Macroeconomic assessment for the EU 'Climate Action and Renewable Energy Package'", in Foresight and ASSessment for Environmental Technologies Integrated Project, 2009.

[2] OECD-NEA, "The interaction of Nuclear Energy and Renewable: System Effects in Low Carbon Electricity System", 2012.

[3] E. Grand, and T. Veyrenc, L'Europe de l'électricité et du gaz, Editions Economica, Paris (2011).

[4] OECD-IEA, World Energy Outlook, 2011.

[5] M. Godet, Manuel de prospective stratégique, Tome 2

Editions Dunod (2001)

[6] M. Godet, Creating Futures Scenario Planning as a strategic Management Tool, Editions Economica (2001)

[7] W.J. Baumol. On the Proper Cost Tests for Natural Monopoly in a Multiproduct Industry, AER 67, 809-22, 1977.

[8] O. Sartor, N. Berghmans. Prix minimum du $\mathrm{CO}_{2}$ au Royaume-Uni : encore du pain sur la planche ?, CDC Climat Recherche, Point Climat $\mathrm{N}^{\circ}$ 6, 2011

[9] Bordier, C. Développement des énergies renouvelables : quelle contribution du marché du carbone?, CdC Climat Recherche, Point Climat n ${ }^{\circ} 16,2008$

[10] OCDE-AEN. The financing of nuclear power plants, 2010. [11] IAEA. Issues to Improve the prospects of financing nuclear power plants. IAEA Nuclear Energy Series n ${ }^{\circ}$ NG-T-4.1, 2009. 